\title{
Adaptation, tolerance and the "smart" technology era
}

\author{
Liviu CONSTANTIN \\ University of Bucharest, Faculty of Geography
}

\begin{abstract}
The article refers to the addiction caused by a certain part of the modern technology, commonly called smart, a modern man's invention to collect data and for simplistic entertainment. It has direct effects on the environment and daily life, as a quick way to change what would be called normal behavior and cause diseases by the attenuation / inhibition of the instincts of self nourishment, self protection, creativity, ration and authentic values. In the end, it will lead to the natural selection in the most important artificial disaster created by man.
\end{abstract}

Keywords: addiction, smart technology, disaster.

\section{PREAMBLE}

For the time being, the origins of the modern man are considered to be either somewhere in the Near East, or in the European Carpathian area (if we follow the path of the human development marked by writing, the Carpathian Mountain Arch 6500 b.Ch., Mesopotamia 3300 b.Ch., North Africa 1500 b.Ch.), Homo sapiens sapiens winning the battle against Homo Neanderthalis which led to the appearance of the modern races - phenomenon of man's biologic adaptation to the environment.

From an anatomic point of view, some races are obviously different, but what made them completely different is the adaptation behavior which led to different aspects (the tendency of the human bodies to get compact in the cold areas to avoid the loss of heat, respectively the elongation of the members to the opposite effect, the ocular fold to protect the eye and the predominating fat tissue to maintain humidity). The only identical part is the intellectual potential, the races belonging to a single species being proved by the possibility of the crossbreeding. As a conclusion, today we are as smart or as stupid as the first Homo Sapiens Sapiens, the difference is made by our perception, adaptation and tolerance. Then, why don't we have a Homo Troglodytes and a Pan Sapiens? Nowadays someone expects an evolutionary leap based on the smart technology, virtual, fake environment, created by the precise persons who use this environment. Will this unreal environment lead to Homo Sapiens Smarticus or to Homo Troglodytes?

There might be some to protest against this statement, bringing to attention the so-called Flynn effect (https://www. descopera.ro/dnews/ 19.12.2013). The research that has been conducted in the domain with regard to this effect has reached the conclusion that the individuals "have got better and better at solving tests. (...) people are more exposed at all types of tests. Thus, they are able to detect certain rules and to exploit them" as one of the researchers, Michael Woodley, explained. The experiment conducted by Woodley and Elijah Armstrong consisted in assessing the individuals' speed of solving 14 IQ tests by applying rules already learned at school or in other environments. When the two researchers compared the information referring to the Flynn effect for each of the 14 tests, the conclusions were astonishing: the more a test solution depend on rules, the more the Flynn effect is observable. This conclusion suggests that the Flynn effect is not caused by an increase of intelligence, generally speaking, but by a better individual's ability to solve the tests more easily by detecting the rules to be applied. The two researchers finally stated: "The existence of the Flynn effect does not mean that people become more and more intelligent, but they develop a wide range of limited cognitive specializations." 
Let us go back to behaviors, the modality of basic adaptation of the mammals. The mammal behavior, so man's behavior, is very varied, even infinitely varied. If, at present, there is only one Noble Prize awarded for the study of the mammal, bird and insect (bees only) behavior by the researchers K. Lorenz, N. Tinbergen and Karl von Frisch in 1973, the prestigious Swedish Academy has not succeeded in awarding such excellence in the study of the human behavior up to date. Nevertheless, a multiculturalist, Singer, declared with nonchalance in his compendium that "today we know we have found the logarithm of the human behavior" (Singer, 2006). Then, what does refrain the renowned academics award him the prize for his merits in deciphering the complete human behavior? Is it exactly that the respective behavior cannot be standardized completely?

If we agree with Singer, we could formulate the complete diagram of our behavior using the smart technology. Yet, there is an unknown factor in the equation and it is given by the environment. The evolution of the human being was based exactly on the adaptation to the environment, which had as an initial result the distinction from the other primates, and later on from the other forms of Homo. Comparing the whole history of our planet with its different heating and cooling periods to the human history, the latter has a lot less experience, but a spectacular adaptation. If the human being had appeared earlier, getting more experience, maybe there would have been a different form of Homo today to defeat genetically Homo Sapiens Sapiens. Nowadays the challenge is double. In addition to our environment in permanent change (natural - the planet getting older, and artificial - industry and exploitation), there has appeared a so-called virtual, fake, artificial environment called the internet, with specific mechanisms of socializing, data communication, etc. If we also take into account that this fake environment that requires human adapting was initially created for research purposes but has turned into a weapon ${ }^{1}$ we will have the complete picture of the present "war" of human adaptation. The first interconnection of two

\footnotetext{
${ }^{1}$ See www. profs.info.uaic.ro (2018) where it is mentioned that the technology based on the computer and interconnection was asked for and used by the US Department of State Defense)
}

computers at a distance was made in 1966 at the initiative and with the support of the ARPA Agency of the US department. A TX-2 computer from the Massachusetts Institute of Technology was connected, through the intermediary of a dedicated communication channel to a Q-32 computer belonging to the company System Development from Santa Monica. One of the first networks with commutation of messages was AUTODIN I, developed in the mid 60 s by the company Western Union for the US Department of Defense.

At this point we will structure the objective of this article. We have to mention that this issue has not been discussed before, or if it has, we do not know. We could add that accusations of empiricism might be formulated with address to the author of this article. Even so, it must be admitted that the problems of our modern society as they are raised in the article can be easily noticed nowadays by a keen observer. We will continue with the chapter structure of the text.

\section{WHAT IS BEHAVIOR?}

Behavior is generally defined as an observable activity of an organism, an interaction with its environment. More complexly, it represents the total of the observations, analyses and conclusions about the different types of thinking, culture and reactions of people within a well-defined society. The basic behavior is studied by the science called Ethology which deals with the study of the animal behavior (skills and habits).

Mammal behavior can be extremely varied, social or solitary, active or passive, peaceful or violent, etc. ${ }^{2}$ If we follow the most often met behavior since birth, we find the one of nourishment (food), the new born offspring looking for the mammal's glands in the first place. The next one that can be standardized is the sexual behavior, which is instinctive and appears at the weaned offspring when they reach the sexual maturity to perpetuate the species. It is a very spectacular and creative behavior including wooing, fights, races,

\footnotetext{
2 According to the Biology Student Book for the $7^{\text {th }}$ grade (1998), ed. Pedagogica.
} 
demonstrations of strength and color to impress the pair. These would be the two instinctive mammal behaviors. The rest of them are random and are acquired by learning. This proves that learning is not the privilege of the modern man, but of all mammals, generally speaking. The first learningbased behavior acquired during life is the self defense behavior. This behavior is the exclusive privilege of the mammals, the offspring learn it from their parents, since they are not born with already acquired instincts like the fishes, snakes, birds or insects, and they need their parents help for protection. Why have the mammals lost this instinct compared with the fishes and birds? Man can be found at the most evolved extreme of the mammals and we can understand that his protection only depends on his level of education; the "smart" technology exposes man rather than protect him. The impact with the environment, natural calamities, disasters have forced man to get permanently adapted, leading inevitably to the development of Homo Sapiens Sapiens.

Considering that the self-defense behavior is learnt the questions that arise are: how many of today's schools educate their students to such behavior? And how many of the virtual space users have acquired education for data protection?

\section{FACTORS INFLUENCING HUMAN BEHAVIOR}

Human behaviors are closely connected with the individual's health (physical, psychical and social) and the factors that influence a population's (formed of at least 3 individuals) health (biological, demographic, sanitary, ecologic, from the physical and social environment ${ }^{3}$ ).

Biologic factors - manifest their influence on health by the varied reactions of the individual, by the adaptation to the environmental conditions in permanent change (so human behavior is also in permanent change and adaptation), and by the heredity (normal or pathologic). The predisposing

\footnotetext{
3 According to WHO http://www.who.int/publications/en
} (2018). nature of a carrier or of their family is taken into account so as to prevent hereditary diseases. The sex and age are the individual's variables which show the state of health from the point of view of the birthrate, fertility, mortality and physical development. Today it is easy to notice that the young generation suffer from diminished birthrates and fertility, disharmonious physical development, obesity. All these are the result of modern education (or even lack of education) that places the individual in the middle of their own interests, barely leaving room for another human being - a possible child - to be cared for. The financial factor is to be considered too, in the families that feel they cannot afford to offer o proper future to a possible child. Moreover, the old generation is characterized by increased mortality because of the boom of cancer cases and of diseases with unknown etiology.

Demographic factors - have a strong influence on the dynamics of the state of health of the population, considering the number, density and the degree of dispersion, but also the structure of the population and its dynamics, including the geographic and social mobility.

Sanitary factors - reflect the degree of development and efficiency of the sanitary services (which are disastrous at present because of the deficient quality of the medical treatment precarious university education, the massive corruption, etc.). They increase or decrease morbidity according to the successes of the modern medicine, but also from the perspective of the involution of a society (technology cannot be offered to a tribal population since it will cause more harm than good). Our mentioning of these factors might cause debate given the latest progress registered in the medical field. Nevertheless, we should be fair and admit that not all countries, even regions worldwide benefit from it (what is called the "third world countries"). Even sadder, not all the people in the developed countries enjoy the medical progress, because of financial reasons.

Ecologic factors - come from the social and the physical external environments, by the adjustment to the environment and the change of lifestyle and 
work, but also the nature of work (the virtual environment is included here which denotes antisocial behavior, with false adaptation at an unreal environment and direct action on the individual's health).

Factors from the physical environment - are cosmic, hydro-meteorological and geo-climatic. We evaluate the so-called physic agents (radiations, dust, and temperature), chemical (aliments, gases, toxic substances) and biologic (microorganisms, parasites, viruses). They are inter-dependent with the social-economic, cultural and sanitary factors.

Factors from the social/cultural environment - the behavior is given by the social environment of the individual (drug, tobacco, coffee, energizers consumption, unemployment, illegal work, politics at the work place, the use of the smart technology, etc.). These lead to the conceptualizing of deficient behaviors and psychical disturbance taking into account the individual's culture (Devereux, 1998).

Strategies of prevention: 1 give life to the years (measures of control of morbidity and incapacity), 2. give health to life (promoting a healthy behavior and eliminating the antisocial virtual environment), 3. giving years to life (decreasing the number of premature deaths and increasing lifespan).

What is taken into consideration into this article: the process of acquiring the attitudes of value (models of behavior generated by universes of value) - the duty towards ourselves, others, the social or politic, etc. organization, the work colleagues, the society we come from and to extend it, the duty towards the universal society. The mechanisms involved in the state of health and disease at a behavioral level, to the psychotherapeutic orientation are: the psycho-dynamic approach (psycho-analysis: Freud, Jung, Adler, Fromm, etc.), the cognitive-behavioral approach (Ellis, Wolpe), the humanist-configurational approach (Rogers, Perls).

Value behaviors get developed by the correct definition of a situation (which is affected by the virtual environment nowadays), the involved values, respected principles and setting loyalty (the disappearance of the human empathy, massive selfishness, narcissism, the disappearance of kindness) and the logical action (a range of activities which aim to the accomplishment of goals which appear in the subject's conscience, but are recognized by the majority of population) (Pareto, http://www. yourarticle library.com/sociology/paretos-formulation-of-logicaland-non-logical-actions-of-human).

Smart technology can affect directly human evolved behavior - taking into account the research and the psychiatric compendiums which are based on the behavior deficiencies and/or unconformable: the behavior of knowledge and research (the technology infers and offers false, marketing-type needs to the individual, which leads to the reduction or destruction of rational research and the overestimation of curiosity), the affective behavior (the introduction of selfishness and narcissism as common values in society), the civic-social behavior (the virtual environment is a source of the antisocial behavior), the aesthetic/artistic/creative behavior (the introduction of the ragged, slack, erotic dress code, considering obesity as normality and beauty, instead of being considered a disease in evolution, Predescu, 1989), socionics (the definition of the relations between individuals based on the personality type and their predictability) and telepathy (feeling from the distance and general empathy/the disappearance of the human spirit).

We follow/identify the negative lifestyle and the risk factors for the physical, psychical and social health, the alteration of the above mentioned factors, we create strategies for their control and improvement (see the phenomenon of the forbidden smoking in public spaces nowadays, but accepted and promoted in the 1930s vs. the technologic antisocial behavior (smart) - perhaps in 20-30 years control laws will be implemented), since health is promoted by behaviors characteristic to the healthy lifestyle and the formation of human evolved behavior is a prediction of the state of health (e.g. factors such as the sedentary life and unhealthy food - the exacerbation of consumption/trade as lifestyle, entrepreneurship as a way of survival under the capitalist regime, determine the increase of the cardio-vascular risk factors ${ }^{4}$.

\footnotetext{
${ }^{4}$ See the INTERHEART study dealing with the nine traditional risk factors and the specific ones or the EUROASPIRE studies I, II, III - https://www.medscape.com/viewarticle (2018)
} 
Human behaviors are the so-called evolved ones which help the individual relate to the realities around (real or virtual nowadays) by self-projection, attitude and preferences, so guiding his social and individual actions. This axiological base of relating represents the total of the individual mobiles and super-individual norms which are interiorized by the individual who applies the set of values. In this case we could come to the conclusion that, in fact, the evolution towards Homo sapiens was due to the crystallization of this axiological space emerging from real social actions, at the same time being their ferment. The introduction of smart technology and virtual, fake space should either crystallize a different axiological space, or develop/ inhibit the present space which led to de evolution of the human being (real valorization).

The genesis of values relies on the historical stages of knowledge. Thus, there is a valorization based on origin, reflections of the objective properties (naïve realism) and objectivity/ transcendentalism (objective idealism) (Popa, 1972). At present, the valorization through the smart technology is definitely based on subjectivity and flagrant manipulation. The perception is deeply affected, and the adaptation is false. To distinguish between good and bad becomes almost impossible rushing to value reversal. This aspect is found the most clearly in the perception of risk in general, and cataclysms in particular, which becomes nonexistent. The sensorial sensitivity and subsequently the logical one become uninvolved or involved in a wrong direction (see the reversed tolerance behavior). A part of the international mass-media, advocate of the "traditional values" has already started encouraging the self-defense behavior using attention drawing articles such as: "This is an apple. Some may try to tell you that it is a banana. They may repeat "banana, banana, banana" over and over again. They may write the word "BANANA" in capitals. You may even start believing that it is a banana. But it is not. This is an apple. Facts first." This is the text written over the simple and bright image of a red apple against white background presented in the CNN campaign of fight against mass manipulation and fake news in $2018^{5}$. If the

\footnotetext{
${ }^{5}$ Agerpres ( 2018) https://www.agerpres.ro/cultura/sci\&tech
}

obvious things can be so grossly manipulated so that perception should be deeply affected, all we can do is come to the conclusion that the nonformal education, especially the electronic, unprotected one is at war with the formal, traditional education. But what is to be done when the formal, traditional education is affected by the reversal of values caused by the decision factors educated non-formally at the "smart" type of life school? They will generate indirectly reversed values or lead society by perverted educational policies. Even worse, what is to be done when there are individuals affected by the "apple - banana" syndrome in the structures of defense during disasters or in the firefighter brigades, police, civil defense?

This type of syndrome could be characteristic ANAF (National Agency of Fiscal Administration) - www.anaf.ro, which encourage tax payers using letters paid by the same tax payers to use exclusively the "Private Virtual Space" (is there any term of privacy in the electronic environment? See Wikileaks which reminds that everything is public) and send sensible data such as the CNP (numeric personal code) electronically. This ideology is grounded by the "smart" societies whose aim is to reach a technological globalization such as the "smart city", "smart shops", "smart map", "smart caravan", etc. In fact, they only want direct, big profits based on routine, comfort and tolerance of a non-reactive population and unable to defend themselves. Another public institution, SRI (Romanian Department of Information) www.sri.ro, whose goal is to protect citizens and society, in general, draw the attention of the modern technology users in its Guide to the population that "The firs rule of Internet navigation is to stay as anonymous as possible". This means one must not make personal information public (complete name, address, telephone number, CNP, passwords, family members' names, credit card numbers). The majority of credible people and companies will not ask you to send them this kind of data on the Internet." This is how SRI defines ANAF by analogy as a non-credible institution! If ANAF is only an economic institution which can affect the budget of a person or institution by the reversal of values, what is to be done when institutions such as 
Ministry of Education, Health, Defense, Civil protection are perverted through the intermediary of "smart city", "smart country" etc. projects?

To reach this objective we should follow how the evolved type of human behaviors studied up to now would react, to be able to understand the modern individual's adaptation at the electronic environment. To play with imagination, theoretically speaking, there might not be such thing as breast feeding anymore, but "modern" methods involving substitution chemical-biologic substances. Accordingly, the offspring would not benefit from the antibodies transfer from mother, the alimentation already filtered by mother and would not instinctively look for the breast, but an electronic device would announce the time of the meal providing the replacing substance. The human reproduction might happen in the laboratory by modern methods, the sexual intercourse being getting to be considered degrading. The defense could be the privilege of a third party.

\section{THE EVOLUTIONIST PERSPECTIVE (?)}

This chapter will bring arguments in favor of the hypothesis that the notion of tolerance, as spiritual individual's defense mechanism, has known conceptual changes in both its Christian and philosophical meaning in modern society as an attitude of non-defense against individual and eventually collective moral unstructuring.

It was not good, beautiful, easier life that was the foundation of human evolution, but effort, problems and trouble caused by the continuous adaptation to a hostile and full of hardship environment. Cataclysms, natural disasters, severe life conditions made it that Homo Sapiens Sapiens to be the only mammal that can survive anywhere on the Earth, even more, in the cosmos (extremely hostile to life). Thus, self-defense proves to be the adult's main behavior in front of the unknown, imminent attack and disasters. And still, humans and mammals have lost this instinctive defense behavior which can be found in fishes and birds. The aim of this chapter is to provide arguments supporting the hypothesis that tolerance - a spiritual behavior which combines most evolved behaviors - has started to lose its basic meaning and purpose. First, tolerance is a Christian attitude, it is a learned behavior, a condition of evolution when the individual or society are strongly protected. The tolerance of diversity as an expression of the love of creation represents the evolutionary leap from animal to spiritual human. But the correct behavior also includes intolerance against all factors that could destroy creation or could estrange the individual from it. To be able to make a distinction between the two attitudes the individual need discernment. Unfortunately, we could say that discernment is destroyed by the smart technology. Therefore, when faced with the alteration or disappearance of the defense behavior, tolerance is out of place, its involution reaching the basic behavior.

Tolerance is also defined as habit or the disposition of the organism to deal with certain environmental conditions (unfavorable, tough). Sociologically speaking, tolerance is a "non-combat" type behavior of adaptation when the individual has to face a negative, aggressive behavior (stress). Thus, as we have already stated above, tolerance should be an exception in the general human behavior. Education today, as it can be noticed by the values imposed by a certain well-defined society, teaches mostly tolerance and not the defense mechanisms as they were defined initially. When tolerance is imposed, and it is not an expression of the organic disposition, then the organism suffers and regresses. Values cannot be imposed on the individual, but they need to be taken upon the individual, and Homo Sapiens Sapiens who owns a defense mechanism (cultural, spiritual, educational, sanitary and, in the end, physical, rational) will get in conflict with the one coming to his rescue during disaster if this one has a wrong perception and reversed values. Some people's "tolerance" at floods, earthquakes, fire, social conflicts, etc., when others try to save them only represents the abandon of the defense behavior, if they ever had it. Changing the concept, as Wikipedia ${ }^{6}$ does: "the respect for other's freedom" (including negative, aggressive, anti-traditional behavior), will only lead to the exception to become

\footnotetext{
${ }^{6}$ We chose to mention Wikipedia because it is editable by all, so that it could be considered a carrier of modern points of view and perspectives.
} 
rule. Moreover, in our language the term "lenient" is used as "forgiving" with the meaning of tolerant, but one can only forgive a mistake, not a wrong behavior. If we consider the terms "being wrong" (intentionally or not) and respect (for the other's freedom) equal, we could realize the greatest destruction of the evolutionary behavior. The evolution did not happen through mistakes, but through the crystallization of the axiological space that emerges from real social actions during difficult moments for the human being. If the individual had not valorized the loyalty to the collectivity, tradition and what is good for himself and then for the others, he would not have been constantly able to come back to his former state of "normality". Or, for the human being normality means morality. Unfortunately, morality has many needs, and failing to provide for them leads to immorality. In time, normality means culture, as the totality of thinking, attitude and action patterns. Culture consists of ideal components (beliefs, norms, values, models of action) and material components (tools, houses, clothes). It teaches how an individual should behave to the family and society members, for instance to the unknown persons. In a society where symbols, rites, language, traditions are predominant, people will be open, kinder to strangers, but also more "corruptible" and "tolerant" (Ianosi, 1977). In a society where norms, laws, and customs are predominant, people will be false, irrational, lazy, lacking culture, immoral, amoral at the best. Real culture allows people to adapt to the environment and survive in difficult situations, since, biologically speaking, the human being is weak. If we have weak or false culture, the individual's defense behavior will be diminished or lost.

If in politics, Nazism, communism, and the more recent neo-liberalism aim to the "new man", without religion and culture, international, in the technical domain, the smart policy has the same goal. The members of the Romanian Academy have recently reacted to the proposals of "smart", parental education: " The project of the Ministry of National Education of issuing a law for a system of parental education without any Romanian specific, with explicitly stated implications against the traditional family as nucleus of the social, cultural, moral, Christian, millenary Romanians' life, supposes a unitary education of the children with no differences according to the sex, anthropologic and psychological, community environment (rural, urban, etc.), ethnic peculiarities. This project is an attempt resembling those from the states with totalitarian, internationalist or global regimes to obtain what has always been called "the new man", without family, nationality, country, identity." "The Romanian Academy considers that "in the year of the Romanians' Centenary of the Great Union, when the evaluation of the Romanians' exceptional successes is done, educated in the spirit of our traditions, giving up on these traditions would mean an act of national betrayal". This is how The Ministry of Education defines parental education: "Social inclusion by providing integrated social services (smart - n.a.) at the community level". This language is specific to the totalitarian societies as the Romanian Academy stated.

We consider the smart type educational process as an alternative at the teacher's choice, if they consider that the students are open to it (some students in the real-study classes). The "humanists" will ask for the traditional education which implies human interaction, valorized by feelings and self consciousness. The "Lottery" (XOY) behavior involving only three behavior patterns, a left one, a right one and a middle one only represents the present global economy mechanism where the infinity of the other adaptation behaviors developed by the individual are ignored (just like the researchers who were awarded the Nobel Prize and who standardized only three behavior patterns for the birds, animals and insects - bees). The XOY behavior can be found in politics, too where the human beings could not overpass the level of left, right and some middle political parties. Why does it happen? (Constantin, 2013). As a conclusion, the Romanian Academy is right when stating that "giving up on these traditions means an action of national betrayal", an action of humanity betrayal, we would say. People should not be tolerant to the electronic environment, but they should have the ability of defending themselves against it, and mainly of selecting it. The electronic environment

\footnotetext{
${ }^{7}$ www. acad.ro/mediaAR/pag_media_pctVedere.htm (2018)
} 
should only be an alternative to our daily lives, not an obligation. Why do the important hotel chains forbid the use of modern technology during the moment of tourists' relaxation? Why have programmers, such as Sean Parker, the Facebook founder or Steve Jobs, the Apple founder forbidden their family members use their own electronic programs? We must not do what technology says, but technology must be able to adapt to our needs, requirements, to our use and easier life. "Quod erat demonstrandum", programmers cannot foresee the majority of the human behaviors, so that the technology developed by them should adjust anywhere on Earth, but they only develop limited programs that force the users to learn what the programmers want them to. Since the present market economy relies on "educating" the consumer (the Pavlov effect), then the commercial boom of the "smart" technology is understandable.

When faced to the natural disasters, and even worse, to human-induced ones, the modern individual, who is extremely tolerant, is selfcondemned to exitus. In order to be able to fight for the other's rights, one must be able to fight for their own rights. In order to be able to protect the other, one must be able to protect themselves (Ianosi, 1998). The reversal of values used by the smart technology at large scale today has had as results spectacular involutions in the evolved human behavior. The individual's freedom of living, expressing themselves as they wish, even negatively and offensive about the values built by Homo Sapiens Sapiens based on the evolutionary historic axiological relations, annihilating the beauty, civicsocial, and affective human behavior represents, in fact, the loss of the self-defense behavior. What is more, the value reversal through the commercial, smart-type behavior, "Rom-English" (language mixture), presenting notions with different meanings, duplicity, in general, on behalf of general and individual liberties, together with questioning some international norms such as the Man's Rights, certain Conventions regarding the environment or the elimination of mass destruction weapons to the direct and short term benefit of certain closed societies miming democracy (open society) will lead, at least, at important breaks in the human behavior.
Humanity has developed specific behaviors trying to become better. Technology, starting with the sickle (on our territory - Romania - a sickle dated from approximately 6300 years ago has just been discovered $^{8}$ ), up to the today's sowing machines - has contributed massively to the development of the knowledge and research behavior for an easier life, the food behavior being the essential one. On the other hand, technology has contributed to the rational development of the defense behavior with direct effects on the art of beauty and civic-social behaviors. But what could be done when technology is not used to the society's advantage as it has been meant to, but to the advantage of closed societies, the defense behavior being replaced with the warlike and tolerance behaviors? Can the individual fight against the environment? How much can the individual tolerate the real or virtual environments? Professor Jean-Francois Toussaint declared from the University Descartes, Paris, France ${ }^{9}$ : "The decline of the human abilities that can be seen today is a sign that the environmental changes, including the climate, are contributing to the increasing of the number of constraints that we have to take into account at present. Observing the decline tendencies can offer an early hint that something has changed, and not for the good. The people's height decreased during the last decade in some African states; this fact suggests that some societies are no longer capable of offering enough nutrients for each of their babies and maintain their younger inhabitants' health". Will Homo Sapiens Asistatus (modern man assisted by technology) lose the acquired skills, and become a Homo Sapiens Troglodytus? The famous professor went on: "While trying to overcome the environmental restraints, people might need more and more energy and investments to restore the balance between the pressures set on the ecosystems. But, if this is accomplished, we will assist at an increment of the average values of height, life expectancy and the majority of human bio-markers." ${ }^{10}$ So, technology can be blessing and curse at the same time. Nowadays, most people are

\footnotetext{
${ }^{8}$ See the "Museum of Dacian Civilisation", B-dul 1 Decembrie Nr. 39, DEVA, Hunedoara, www.mcdr.ro

${ }^{9}$ Agerpres, https://www.agerpres.ro/cultura/sci\&tech (2017)

${ }^{10}$ www.medscape.com/voirarticle (2018)
} 
constantly connected to the "smart" technology by the electronic devices.

\section{DISEASES CAUSED BY SMART TECHNOLOGY}

In this chapter we will try to highlight the main behavioral alterations as result of the psychological changes induced by the overuse of smart technology as mentioned in chapter 4 . The scientific research in the domain is only at its beginning, although C. G. Jung was able to draw attention on the start of behavioral changes in the 50s (Jung, 2015): “(...) we have fallen into an abyss of progress which pushes us violently towards future, pulling us even harder from our roots. (...) it is exactly the loss of this bond with our past, the lack of roots that cause such a discomfort in civilization, and such hurry, that we live more in the future and in a virtual promise of a golden era, than in the present up to which our evolutionary fundament hasn't even arrived. (...) the hope of more freedom is annihilated by an increased slavery toward the state, not to mention the awful dangers we are exposed to by the most brilliant progresses of science. The less we understand what our ancestors looked for, the less we understand ourselves and bring our total contribution to the amplification of the individual's lack of instincts and roots, so that, becoming a mere particle in the crowd, he only follows the spirit of gravity."

Nomophobia (no-mobile-phobia) is a disorder caused by technology, but also by its absence, represented by the fear of being left without a mobile phone. Gadgets (electronic toys) have become a continuation of their bodies for certain people, and their loss can cause panic attacks, difficult breath, and trembling, sweating, acceleration of the heart beats, chest pains or nausea. The fear of not having the mobile phone is caused by addiction. When a person is physically or mentally addicted to something, they cannot find a way of escape. People are social animals which need constant company, communication and contact with the others. Subsequently, this phobia is not totally unnatural, considering that the mobile is handy, quickly available and used by persons of all ages. The most vulnerable and attached to the mobile phone are the children, teenagers and the elders who, preoccupied with it, get almost completely disconnected from the exterior world. They can be seen bending over the mobile while walking in the street, during breaks at school, sometimes even during classes or courses, at home, at the table, and when going out with friends. But there are more dangers. Except for the nomophobia, using the mobile without limits causes memory weakness, and the inability of developing memories. Anatomists draw attention on the fact that the spine is bending more and more to the front as people use tablets and mobiles.

The long-lasting incorrect posture causes the disease called Telepressure ${ }^{11}$ (Fig. 1).

But what are smart technology and/ or artificial intelligence, basically speaking?

If we consider the terms separately, smart technology represents the multifunctional technology which can accomplish more tasks in a single device. Artificial intelligence was introduced by John McCarthy in 1995 and it is supposed to "aim the study and design of intelligent agents, systems that perceive the environment and maximize the chances of success through behavior". But the intelligent agents are calculation machines, in fact, modern man's tools. If we take into account the implications of the word "intelligence" - the ability of understanding the essential easily and correctly, solving new situations or problems on the basis of previously acquired experience (cultural, spiritual and real perception mechanisms), then the introduction of certain sophisticated computer programs as artificial "intelligence", in the absence of their developing of cultural, spiritual and real perception mechanisms specific to the human being, only represent an elimination/ attenuation factor of the defense behavior. The desire of creating a powerful artificial "intelligence", based on selfconsciousness is predestined to failure; almost all intelligence simulations rely on rules and common algorithms, the progress has been done only in the field of the basic one (e.g. oral and verbal recognition, automatic translation from one language to another and chess). If we take into account that artificial "intelligence" cannot go

\footnotetext{
${ }^{11}$ Public image - www.ncbi.nlm.nih.gov/pubmed (2018).
} 
beyond the animal intelligence (another field of artificial "intelligence" studies animals, especially insects, which are easier to imitate by robots, but satisfactory computational pattern to simulate animal intelligence could not be created).
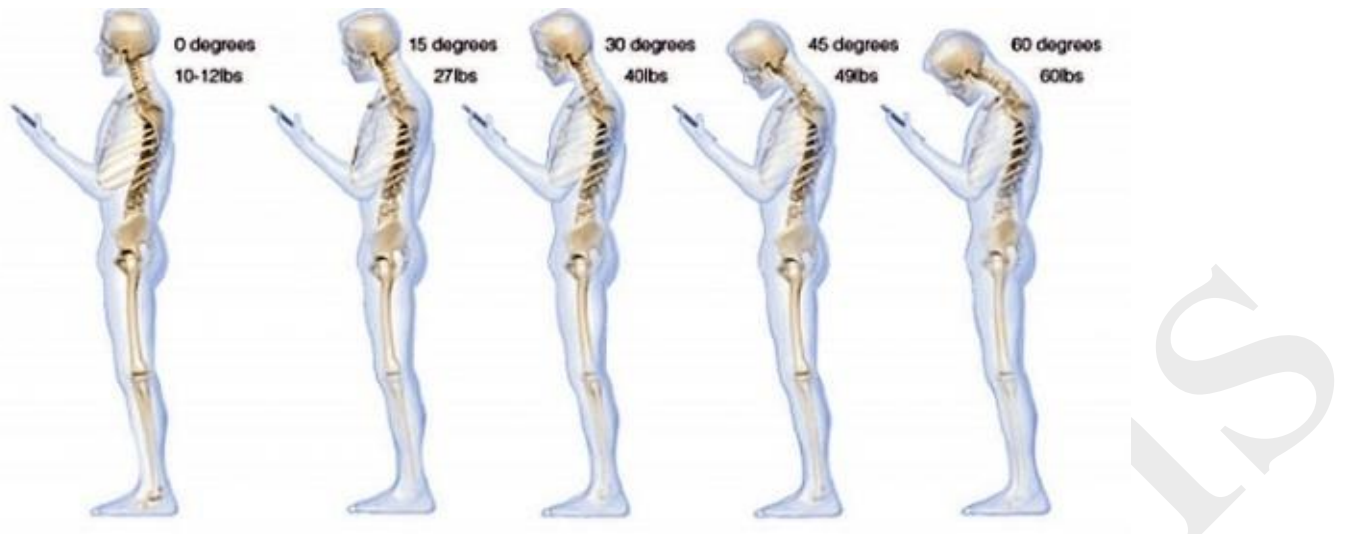

Fig. 1. Telepressure. Kenneth Hansraj, Head of the Surgery clinic at the New York Spine Surgery and Rehabilitation Medicine, states: "At 15 degrees inclination to the screen, there are 12 kilograms of pressure on the spine, at 30 degrees 18 kilograms, at 45 degrees 22 kilograms and at 60 degrees no less than 27 kilograms"

Another argument in favor of our theory that advanced technology needs advanced self defense mechanisms is brought by general Nicolae Ciuca, Head of the Major State for Defense (SMA), whose declaration was presented by Agerpres: "Endowing the army with modern fight equipments must be done at the same time with the training of the staff who is to use them. (...) Educational plans and school curricula must be adapted as well as possible to the major technological changes and to cover all innovations in the military field.(...) We need all is called perfect communion inside this technique man binomial, so that, in the end, we could say we have accomplished a capability". To sum up, we do not throw away the traditional education, but it has to include and adapt the major technological changes!

"The majority of smart category devices offer comfort, not security", declared Mircea Grigoras, deputy general manager of the National Center for Response to Cybernetic Security Incidents (CERTRO), during the conference "Cyber threats \& Cyber security Day" (CERT-RO, 2017). "Today we have the possibility to connect almost any type of household devices to the internet, including coffee machines, air-conditioners, surveillance cameras and systems, alarms, doors. There are doors using a 'Bluetooth' connection to open in front of the owner when he approaches and has the mobile in his pocket. These are highly demanded products. Their majority aim to the user's comfort. Having comfort is extraordinary, but, at the same time, one must be very aware that when posting information on the internet, one enlarges the attack area", the abovementioned manager said. We wonder rhetorically: WHO is attacking WHO? If we mention attack, do we also mention defense behavior? Moreover, in the USA there are concerns for the protection of those who should learn from their parents about the defense behavior. Civic American societies state that "smart" watches, instead of protecting the children, could make them vulnerable to piracy or computer criminality. "Seemingly supportive for parents who want to protect their children, in reality these smart watches endanger the little ones", Josh Golin stated in an official announcement, from the association "Childhood without publicity" Programmers and content creators who contributed to the success of campaigns such as Google, Twitter or Facebook, and Justin Rosenstein (co-founder and head of production of software company Asana) deny their own creations and send their children to elite schools where they are forbidden to use mobiles, tablets, even laptops. At present, there are voices which started to be heard warning that not only does it cause addiction, but this mobile device technology also brings its contribution to the severe

\footnotetext{
${ }^{12}$ Agerpres, author: Simona Tatu (2018) https://www.agerpres.ro/ cultura/sci\&tech.
} 
limitation of people's abilities to stay focused on their activities and even to the IQ decrease ${ }^{13}$. The mere presence of "smart phones" affects the cognitive capacity, even if the device is turned off. "Everybody is distracted (by these devices) all the time", Rosenstein added ${ }^{14}$.

A reversed behavior pattern was sanctioned by the Manager of the Cannes film festival, too, in 2018, using the logo: "We want to bring decency back". He called the selfies "grotesque and ridiculous" photos, threatening the film lovers present at the festival with the exclusion ${ }^{15}$. If today the environment turns against us because of our negative actions on it (massive industrialization and exploitation) and even we turn against ourselves using smart technology (the loss of the defense, art of beauty, human affection, etc. behaviors), then the modern individual's adaptation becomes critical, if not impossible. Sean Parker, founder president of "Facebook" reminds that the network was created to waste the users' attention and time as much as possible, and, in our country Mr. Gabriel Botnariu, member of the Health Department in the Romanian Parliament has declared recently that urgent measures need to be taken to invest in the children's and youth's mental health and welfare to eliminate the social maladjustment caused by the "social media" which is a social scourge. If not, then we will have the correct dimension of the disaster upon the individual today (the massive mental health affliction $)^{16}$. An initial symptom is recognized by doctors under the name of "body dystrophy disorder", which means an obsession related to a perceived body flaw. If, for instance, make up was created to cover face flaws, nowadays the tendency is reversed by the irrational use of the "smart" technology. "Applications such as Snapchat, Instagram or Facetune highlight a new reality of today's beauty". An article published online by the American Medical Association mentions: "All these applications allow the instant alteration of the individual's aspect according to completely

\footnotetext{
13 Test Sprint Mind (2018).

${ }^{14}$ Agerpres, https://www.agerpres.ro/cultura/sci\&tech (2017).

${ }_{15}$ Agerpres, cultura (2018).

${ }^{16}$ www.raportuldegarda.ro (2018).
}

unrealistic standards" $" 17$. Thus, the society gets an unhealthy idea about what people should look like or how they should behave. The result is that people start forming an altered self-image while their need of getting a rhinoplasty or facial lifting cannot be objectively supported. Most of the times a psychologist is the one that can bring the situation to normal. The lack of professional support for such individuals leads to self destruction. Self distrust and continuous dissatisfaction are basic signs of behavior deficiencies.

Another phenomenon is to be noticed at the young intellectuals who adopt a specific outfit: earplugs, rucksack and ragged clothes. They generally work for multinational companies or, more tragically, in the academic education field, promoting "sharing" without judgment (proof of the lack/ decrease of the defense behavior). The lack of attention, selfishness and carelessness are chronic behaviors caused by the absence or loss of the abstinence behavior, the action of "sharing" representing the exact opposite.

"The world's and people's digitalization do not clean the social reality of its inequalities, or of its other issues. In this tendency it is easy to see the loss of intelligibility and the reign of binary ambiguity. The bigger the data volume, the greater the possibility of being algorithmically correlated. The human being will not dream and hope anymore. The "group shaped" individual does not have the possibility of own and private development. (...) Making a decision is not equal to obeying the result of a virtual calculation. The human subject disappears behind data about him. "The speed of information is more important than knowledge, logos - than words and ideas, corpse images - than the ones with people alive. What can be done?", CMR President, dr. Gheorghe Borcean stated in March, $2018^{18}$.

We should take into account that modern smart technology can be used correctly and safely only after the age of $12-14$, when the young are able to acquire moral and civic-social defense values. On the other hand, it is known that "the activity of the

\footnotetext{
17 www.ama-assn.org (2018).

${ }^{18}$ www.cmr.ro (2018).
} 
human brain starts slowing down and the cerebral decline installs after the age of $24 " 19$. The effects of addiction and severe limiting of the staying focused on developed activities ability (the Sprint Mind test), the IQ decrease and the blood pressure value increase (stress) with direct results on the cardiovascular system. In addition, a specific protein (beta-amiloide) accumulates in the brain causing vascular dementia, because of the chronic reduction of the blood circulation at brain level. These facts make us wonder what type of evolutionary leap could experience Homo Sapiens Sapiens between 14 and 24 years old.

This disaster was "disseminated culturally" by the French writer Phil Marso who published in 1999 his humoristic novel "Tueur de portable sans mobile apparent" (The killer of mobiles without visible reason), the first thriller whose main character is the mobile phone. On the $6^{\text {th }}$ of February 2001, willing to expand the debate started in his novel, he came with the proposal of having at least one day when people should give up on using the mobiles, or at least reduce the number of conversations and SMSs. These are the International Days without Mobile (February $6^{\text {th }}-8^{\text {th }}$ ) established in 2004 to draw the users' attention on the impact of modern technology on environment and daily life.

\section{CONCLUSIONS}

Is smart technology a real support in the individual's life nowadays? Does it take the individual to the next level of the human physical and mental abilities? As we have stated in the article smart technology and artificial intelligence have both advantages and drawbacks. They are just like any creation: both good and bad. And yet, reaching certain physiological and anatomic limits as great researchers suspect nowadays can be blamed on "certain persons' desire" of taking advantage and controlling society. In fact, the rational, creative individual will find protection mechanisms when faced with the actual disaster

\footnotetext{
${ }^{19}$ See the study conducted at the Simon Fraser University in Canada (2017), https://www.sfu.ca/internationalstudies/ undergraduate/2017.html
}

which is unperceivable by the majority. "Mens sana in corpore sano!" if the mind is not healthy, can we speak about a ready to fight, healthy body? Giving up on fight in favor of tolerance as general not exceptional behavior will make the difference between extinction and survival.

We must also consider the psychological spiritual approach that relies on the expansion of the human consciousness. Along with the technological evolution that aims at transforming the individual into a robot, having a deep impact on his brain, there must also happen a spiritual evolution that would strongly react to this overwhelming technological wave. The deeper aspect of the matter depends upon the inner freedom of the individual who has the choice of becoming either controller or controlled. This can only be achieved through education and self knowledge so that we can develop inner spiritual organs to help us face the dramatic and traumatic intrusion of smart technology in our lives.

Nevertheless, the young generation's lack of desire for the species continuation, the emancipation of the reversed behaviors, the spread of (new) diseases, and the lack of the selfnourishment and defense behaviors, creativity, ration and authentic values, in general, will lead to the natural selection in the most important artificial disaster ever to be created by man.

\section{REFERENCES}

Constantin, L. (2013). "Etica si management sanitar", ed. Amalteea, Bucuresti.

Copeland, J. (1998). "What is artificial intelligence? \& Animats: computer-simulated animals in behavioral research", Blakwell Publisher Ltd., Oxford, ISBN-13: 978-0631183853

Devereux, G. (1998). De l'angoisse à la méthode dans les sciences du comportement, Paris, Flammarion, 1980 [1967 pour l'édition originale en anglais], 474 p. Ed.: Aubier Montaigne, ISBN 2-7007-2186-1(De la angoasă la metodă in științele comportamentului)

Georgescu, I. (1995). "Elemente de inteligenta artificiala", Editura Academiei Republicii Socialiste Romania, Bucuresti.

Hutter (2003). The definition used in this article, in terms of goals, actions, perception and environment, is due 
to Russel \& Norvig, pp. 125-126, Berlin: Springer, ISBN 978-3-540-22139-5.

Ianosi, I. (1977). Varstele omului, Ed. Humanitas.

Ianosi, I. (1998). "Varstele omului", Ed. Trei, Bucuresti.

Jung, C. G. (2015). “Amintiri, vise, reflectii”; consemnate si editate de Aniela Jaffe, p.276, Ed. Humanitas, Bucuresti, ISBN 978-973-50-4888-4.

Luger \& Stubblefield (2004). "Artificial intelligence: Structures and Strategies for Complex Problem Solving”, pp. 235-240, ISBN 0-8053-4780-1.

Phil Marso (2015). Editura Megacom-ik; 1 editia. B016J8J836, Franţa.
Poole, Mackworth \& Goebel (1998). "Computational Intelligence: A Logical Approach”, New York: Oxford University Press, pp. 7-21, ISBN 0-19-510270-3.

Popa, C. (1972). Teoria cunoasterii, Ed. Academica.

Predescu, V. (1989). Psihiatrie. Ed. Medicala.

Russel \& Norvig (2003). "The intelligent agent paradigm”, pp 27, 32-58, 968-972, New Jersey: Prentice Hall, ISBN 0-13-790395-2.

Singer, P. (2006). “Tratat de etica”, Black Well, pp. 508, ISBN 973-46-0243-8

https://arxiv.org/pdf/0712.3329.pdf

http://scholarpedia.org/article/Artificia_General_Intellige nce

http://sfu.ca/sprintmind 